\title{
EL MUSTERIENSE CLÁSICO DE LA PALEOCAVIDAD DEL CERRO DE SANTISTEBAN (MORÓN DE LA FRONTERA, SEVILLA)
}

\author{
THE CLASSIC MOUSTERIAN FROM THE CAVE OF CERRO \\ SANTISTEBAN (MORÓN DE LA FRONTERA, SEVILLA)
}

por

\author{
José JUAN FERnÁNDEZ CARO
}

RESUMEN

Aunque desprovistos de toda relación contextual, los materiales que aquí presentamos, correspondientes a lo que fue la cavidad de Cerro Santisteban en Morón de la Frontera (Sevilla, España), ponen de manifiesto la presencia de un musteriense clásico en pleno Valle del Guadalquivir, donde las puntas y piezas apuntadas poseen una presencia más que destacada. Esta colección se relaciona, por un lado con las industrias detectadas en algunas cuevas de las Cordilleras Béticas, y por otro, con los materiales silíceos de Tarazona II, cerca de Sevilla, donde parecen convivir estos materiales musterienses clásicos con otros de tradición de graveras realizados sobre materiales cuarcíticos.

ABSTRACT Although lacking any contextual relation, the materials which we present here, correspond to what was the cave of Santisteban in Moron de la Frontera, Sevilla, Spain, clearly manifest the presence of classic Mousterian in the midst of the valley of the Guadalquivir River, where the points and pointed pieces amount to more than a significant presence. This collection is relate to, on one hand, with the industry detected in some of the caves of the Cordilleras Béticas; and on the other, with flint materials of Tarazona II, where these classic Mousterian materials coexist with others of graval pits tradition realized utilizing quartzite materials.

Palabras claves Valle del Guadalquivir, cueva, Paleolítico Medio, Musteriense, puntas, sílex, cuarcita.

Key words

Guadalquivir Valley, cave, Middle Palaeolithic, Mousterian, points, flint, quartzite. 


\section{I.- INTRODUCCIÓN}

Los estudios llevados a caboen el Bajo Guadalquivir ${ }^{1}$ han ido dando forma a la secuencia general pleistocena de las formaciones geomorfológicas del citado río y enmarcando cronológicamente las industrias encontradas en el seno de las citadas formaciones. Sin embargo este enmarque aún posee ciertas lagunas que, si bien no representan un obstáculo infranqueable a la hora de ir despuntando la configuración de una secuencia bien establecida, sí limita la posibilidad de estudios comparativos bien fundamentados de conjuntos interesantes pero descontextualizados, al menos así lo creemos nosotros, como el que ahora presentamos. Esta situación agradece cualquier tipo de trabajo sobre nuevos conjuntos líticos por pequeño que sea o carácter que tenga.

El conjunto que ahora presentamos procede de la paleocavidad del cerro de Santisteban, situada a poca distancia de Morón de la Frontera ${ }^{2}$ (Sevilla). La localización del yacimiento, en el contacto de la Depresión del Guadalquivir y los Sistemas Béticos, la hace especialmente interesante, pues puede ponernos en la pista del encuentro de comunidades de ambas áreas de recursos, con sus instrumentales bien diferenciados, según constan en la actuales investigaciones (Vallespí 1990 y 1994; Fernández Caro 1998 y 1999).

Por un lado conocemos unas industrias realizadas básicamente en sílex, propias de los yacimientos de montaña y pie de monte -entendemos que no tanto por su carácter geográfico como por la materia prima que es capaz de ofrecer-, y por otro, conjuntos líticos elaborados mayoritariamente en cuarcita, asociados a zonas de graveras, es decir, a formaciones de depósitos al aire libre, propias de yacimientos de valle, y de acuerdo con el tipo de los depósitos, integrados por cantos rodados de cuarcita casi en exclusiva. Sin embargo, las características de la industrias de la paleocavidad que ahora ofrecemos presenta diferencias claras con las conocidas correspondientes a semejantes estadios culturales en el Bajo Guadalquivir, tanto en sus formaciones como en las correspondientes a los afluentes Corbones o Bajo Genil, a excepción del yacimiento Tarazona II (Díaz del Olmo, Vallespí y Baena 1992; Caro 1999), en el que podemos encontrar algunas similitudes interesantes.

\section{II.- ANTECEDENTES}

El cerro de Santisteban se șitúa al Este de Morón de la Frontera, y corresponde a las últimas estribaciones kársticas del Subbético. Desde la parte superior del citado cerro se contempla toda la campiña sevillana, manteniendo excelentes posibilidades de conexión con los ríos Guadaíra y Corbones ${ }^{3}$.

Utilizado tiempo atrás como cantera, en uno de los frentes apareció un depósito fosilizado en el que se detectaron registros arqueológicos y paleontológicos, si bien se hallaba prácticamente desmantelado existiendo al pie una terrera de proporciones considerables (aproximadamente unos $20 \mathrm{~m}^{3}$ ).

El nombre del cerro se ha hallado asociado a un yacimiento situado sobre la meseta que fue valorado como calcolítico por Vera Reina y Fernández Ruiz ${ }^{4}$ (1991) y Cruz Auñón, Moreno Alonso y Cáceres Misa

1. Estos trabajos, iniciados por E. Vallespí y F. Díaz del Olmo, dieron pie a las tesis desarrolladas por R. Baena, J.J. Fernández, y J.A. Caro, así como a otras publicaciones.

2. El yacimiento ha dejado de existir en la actualidad al convertirse la cantera en escombrera y los escombros haber tapado por completo la abertura que permitió su conocimiento como yacimiento arqueológico paleolítico.

3. El Corbones ha ofrecido una larga serie de yacimientos paleolíticos, todos ellos asociados a sus plataformas aluviales (Fernández 1998; Fernández, Baena y Guerrero 1999).

4. La relación de piezas recoge "puntas de flecha, puntas, dientes de hoz, cuchillos, raederas y microlitos", sin embargo en el dibujo que acompaña tal artículo puede comprobarse que aparece una punta musteriense completa y otra, pensamos, fragmentada, así como una levallois retocada. 
(1993 a y b y 1995). Más tarde, Cruz Auñón y Jiménez Barrientos, en 1996, dieron a conocer la existencia de un nuevo yacimiento asociado a la paleocavidad y que clasificaron de Paleolítico Medio tras una primera ordenación de las industrias recogidas por la profesora Cruz Auñón y un equipo de colaboradores, entre los que se encontraba el autor de estas notas, en enero de 1995, en la citada terrera.

\section{III.- RESTOS PALEONTOLÓGICOS}

Entre los restos paleontológicos localizados se ha constatado un relativo alto número de fragmentos óseos quemados, habiéndose documentado la presencia de cortes que delatan la acción antrópica sobre ellos. Entre los fragmentos que han podido ser identificados aparecen varios huesos de cervus elaphus y de otro cérvido pequeño, que bien podría tratarse de un representante del género Dama; de un gran bóvido, posiblemente bos primigenius; de un caballo pequeño, probablemente equus hydruntinus; otro de un caballo mediano; y de una tortuga, así como numerosos fragmentos astillados irreconocibles ${ }^{5}$. La presencia de estos animales denuncian la pervivencia de un clima mediterráneo de acuerdo con los estudios de C. y G. Finlayson (1999) y de la que inferimos un medio abierto, salvo en las pulsaciones frías en las que los bosques de pinos se harían más extensos.

\section{IV.- INDUSTRIAS LÍTICAS}

El conjunto de industrias que aquí analizamos se halla formado por un subconjunto de piezas recogidas por el ya citado equipo del Departamento de Prehistoria y Arqueología de la Universidad Hispalense de Sevilla en la terrera al pie de la paleocavidad, y por otro proveniente de distintos propietarios que han puesto amablemente sus piezas a nuestra disposición.

Mientras la primera corresponde, como ya se ha escrito, a una recogida exhaustiva de los materiales pertenecientes a la terrera, la segunda presuponemos está formada por piezas de origen selectivo, ya que apenas se han contabilizado en ella restos de talla, los cuales conforman la mayoría en la primera colección.

Como quiera que, desde cualquier punto de partida, el análisis de los subconjuntos sería incompleto (en la colección recogida por el equipo universitario faltarían las piezas más sobresalientes desde el punto de vista técnico-morfológico y en la otra estarían ausentes en gran número las piezas de desecho de talla), estimamos pertinente hacer un todo con ellas, con el ánimo de que de forma global sean complementarias, ayudándonos a conocer mejor el carácter general del conjunto.

El estudio, pues, nace con la grave dificultad de su descontextualización y parciälidad, aumentado si cabe por el alto número de piezas fragmentadas (presentes en ambos subconjuntos, aunque más numerosas en el primero), cuya segura adscripción tipológica es del todo problemática. No obstante, consideramos que el yacimiento tiene suficiente importancia para ser dado a conocer a la comunidad científica en cuanto que su existencia asegura la presencia de un conjunto lítico musteriense clásico en un medio, el Bajo Guadalquivir, donde las características de los conjuntos mesopaleolíticos, propio de las grandes cuencas ibéricas, se alejan de aquéllos que resultan comunes en la vertiente mediterránea y Norte de la península, presentando unas características postachelenses innegables y donde la punta musteriense es prácticamente inexistente ${ }^{6}$.

5. Nuestro agradecimiento a Bienvenido Martínez, quien amablemente accedí al estudio de estos restos.

6. El yacimiento de Tarazona II (Díaz del Olmo y Vallespí 1994; Caro 1999) es el único que presenta una industria en sílex -su inventario ofrece piezas en cuarcita y sílex en proporciones semejantes- con características comparables a las que ahora presentamos, si bien el subconjunto realizado en cuarcita ofrece connotaciones achelenses innegables como es la presencia acentuada 
Debido a esa fragmentación de buena parte de la industria, la relación de piezas tipológicas completas se verá, en capítulo aparte, aumentada con la de las piezas rotas, si bien su clasificación se hallará siempre reducida por las dificultades propias, especialmente en las raederas dobles y/o convergentes que aparecen sin su extremo distal.

En total se han analizado 1.656 piezas, de las que 333 son lascas no retocadas, 697 son fragmentos de lascas no retocados, 15 son núcleos, 13 restos nucleiformes, 331 tipos de la lista normativa de Bordes, y 267 piezas retocadas fragmentadas. Aparte se han contabilizado 117 esquirlas y restos informes.

\section{1.- Materia prima}

La materia prima utilizada ha sido sílex y rocas afines ( 1.526 piezas que representan el $92,15 \%$ del total del conjunto), caliza ${ }^{7}(101-6,09 \%)$ y cuarcita $(29-1,75 \%)$, aunque ha sido la primera la utilizada mayoritariamente. El sílex es autóctono (al igual que la caliza), de cualidades y características semejantes a los que afloran en sierras cercanas, aunque no se puede rechazar la posibilidad de que alguna pieza pudiera proceder de algún nódulo recogido en los depósitos del Corbones, relativamente próximo (10-15 Km.). En cuanto a la cuarcita, los depósitos más cercanos corresponden a los del Guadalquivir, aproximadamente a unos $25 \mathrm{~km}$ al Norte.

Las aristas de las piezas aparecen vivas, con muy leve desgaste (Redondeamiento 0 generalizado), detectándose algunas piezas con alteraciones químicas que afectan sobre todo a los bordes retocados.

En cuanto a las piezas en cuarcita y caliza, poseen un escaso desgaste de aristas, presentando las segundas dificultades para determinar el talón ya que aparecen a menudo astilladas.

\section{2.- Dimensiones}

Existe una homogeneidad manifiesta en el conjunto de los artefactos, contándose muy pocos casos en los que sus medidas ${ }^{8}$ se escapan de las dimensiones medias, especialmente los fabricados en sílex. Podrían citarse un cuchillo de dorso natural, seis raederas y dos puntas levallois en cuanto a dimensiones más grandes que la media. En general podemos decir que se trata de una industria no laminar, aunque la presencia de piezas laminares es marcada. En las piezas realizadas en sílex se han contabilizado, entre las piezas completas no retocadas, 20 láminas $(6 \%)$ y, entre las retocadas, sólo $8(2,09 \%)$.

\footnotetext{
de macroutillaje clásico. La aseveración formulada acerca de que los conjuntos mesopaleolíticos de las grandes cuencas ibéricas se alejan de los conocidos en el Mediterráneo y Norte de la península se halla refrendada por los estudios realizados por Vallespí-Díaz del Olmo en el ámbito general del Guadalquivir, por J.A. Caro en las terrazas del Guadalquivir en los sectores Carmona-La Campana, y por el que suscribe en el río Corbones.

7. El hallazgo de productos de talla en esta materia prima, hecho bastante común en otros yacimientos, se opone a las características de los conjuntos líticos controlados en el Corbones, donde las piezas con huellas de talla son mayoritariamente en sílex y minoritariamente en cuarcita, pero nunca en caliza, a pesar de que la mayor parte de la carga de los depósitos aluviales están formados de esta materia prima. A ello debe ayudar el hecho de que la caliza es muy susceptible de fragmentación por la acción de los aperos de labranza, hecho que nos llena de desconfianza ante el hallazgo de una lasca o canto con una o varias extracciones de esta roca.

8. Todas las dimensiones han sido tomadas en centímetros.
} 


$\begin{array}{lccc} & \text { LONG } & \text { ANCH } & \text { ESP } \\ \text { INTERV. } & 1,00 / 9,30 & 0,85 / 7,50 & 0,15 / 2,20 \\ \text { MEDIA } & 3,90 & 2,79 & 0,89 \\ \text { MODA } & 4,10 & 2,70 & 0,80 \\ \text { MEDIANA } & 3,85 & 2,70 & 0,80 \\ \text { DESV.TIP. } & 1,27 & 0,82 & 0,48\end{array}$

\section{3.- Tecnología}

En cuanto a la industria en sílex, como sabemos mayoritaria, la forma predominante de talla, extracciones lascares y en menor medida laminares, a partir fundamentalmente de núcleos de planos preparados con desprendimiento previo de la cornisa del plano de percusión que adelgaza los talones de los elementos desprendidos ${ }^{9}$, y con ángulos de ataque cercanos a los $90^{\circ}$, nos presenta unos productos acabados con aspecto levallois, especialmente si el retoque previo a la extracción (desprendimiento de la cornisa) se hace más profundo, ya que esto le dará a las lascas laminares y láminas apuntadas un aspecto de puntas levallois de gran semejanza a las verdaderas. Por ello hemos denominado a la técnica de talla de este conjunto "técnica de aspecto levallois" aunque consideramos que la verdadera talla levallois, la que prepara el núcleo para extraer una lasca preferencial, tiene una presencia modesta.

En general, y como corresponde a una industria medio paleolítica de adscripción musteriense en cueva (Horá, Carigüela, Gorham, Forbe's Quarry, Bajondillo, Zájara, Colomera, Las Grajas, Zafarraya, Humo,... por citar las andaluzas), los soportes son mayoritariamente internos, obtenidos a partir de sus núcleos matrices donde la técnica de extracciones subparalelas desde uno o dos planos opuestos (asimilables a núcleos prismáticos) se halla bien documentada, así como la de la talla centrípeta, detectándose, como ya se ha comentado, que una buena proporción de estos soportes presenta en su anverso los estigmas de una talla que consideramos de aspecto levallois.

La presencia de talones facetados es muy continuada por lo que podemos decir que se trata de una industria facetada. Además estos talones aparecen adelgazados en una proporción muy alta, de acuerdo con la modalidad de talla comentada atrás.

El estudio detallado de los artefactos nos ha permitido conocer una industria lítica muy homogénea, también, desde el punto de vista tecnológico. Unido a un formato generalizado pequeño-medio, donde los ejemplares que sobresalen desde el punto de vista morfológico son escasos, comprobamos que existe una técnica de fabricación muy semejante, donde el retoque fue realizado, en la mayoría de los casos, con percutor de poca masa o de materia orgánica, detectándose también retoque por presión, al menos eso desprendemos del retoque cuidado, simple, pero casi lamelar, y poco profundo que vemos en algunas piezas. El retoque es, en general, pequeño y cuidado, y en buena medida profundo, afectando a la morfología del soporte, con un ángulo de ataque que supera $\operatorname{los} 30^{\circ}$, aunque hay algún testimonio de ángulo inferior-retoque plano-, y bastantes más del semiabrupto, generalmente afectando de forma parcial el borde retocado. Igualmente,

9. Esta particularidad técnica caracteriza de forma progresiva las industrias más modernas y especialmente las realizadas en sílex. En el estudio realizado sobre las industrias correspondientes a las formaciones del Pleistoceno medio y superior del río Corbones se ha apreciado una evolución en esta particularidad conforme a la edad de los conjuntos líticos, si bien la presencia es más fuerte siempre en los elementos realizados en sílex. 
se constata un buen número de piezas con retoque escalariforme, casi siempre parcial, habiéndose detectado algún retoque semiquina y Quina, aunque este último de forma testimonial. También existen algunos ejemplos de retoque lamelar, siempre de forma parcial u ocasional.

Debemos hacer mención de que, aunque se cuentan veintinueve raederas dobles, entre las simples se comprueba que algunas presentan un borde opuesto al retocado con magníficas condiciones para ser transformado en raedera y, sin embargo, se dejó intacto.

Igualmente comprobamos la existencia de un buen número de lascas del tipo gajo de naranja utilizadas como soportes para la fabricación de raederas, simples en la práctica totalidad.

Por lo que respecta a la industria realizada en las otras materias primas detectadas, los escasos núcleos presentan una talla primaria (sólo en cuarcita), consistente en la extracción de lascas a partir de planos no preparados, corticales casi todos, que se ve confirmado por los talones de las escasas lascas detectadas.

\section{4.- Tipología}

Desde el punto de vista estrictamente tipológico, la industria responde a las características generales de los conjuntos de niveles de cuevas andaluzas datados en el Pleistoceno Superior, de acuerdo con lo que proporciona el estudio de restos paleontológicos y, como vamos a ver, del de los propios restos líticos, y donde las raederas suponen la mayoría de los tipos constatados. No obstante está caracterizada por el alto número (ciento una piezas completas), en términos absolutos, de puntas musterienses, en relación con otros yacimientos en cuevas estudiados (recuérdese que por la procedencia del conjunto los porcentajes de poco ayudarían a centrarlo entre otros conjuntos arqueológicos de similares condiciones y características). Este número podría aún aumentarse fuertemente si pudiéramos confirmar como tales los veinticinco fragmentos (especialmente los basales) que con características similares a las de las propias puntas musterienses de este lugar, podrían añadirse ${ }^{10}$.

Igualmente sorprende la escasa presencia de denticulados y muescas, especialmente, y de buriles, raspadores y perforadores, en menor medida.

Por otro lado se detecta un acusado carácter apuntado de la industria. La tendencia a la producción de piezas apuntadas ha dificultado fuertemente la clasificación de piezas retocadas en puntas musterienses o raederas convergentes, siendo el carácter "muy apuntado" el que ha primado para su adscripción definitiva en las puntas. Esta problemática también ha estado presente entre las raederas dobles, ya que el retoque ha sido llevado casi a la punta de soportes de contorno apuntado.

La ausencia de macroutillaje es absoluta, si bien los cantos de cuarcita con talla pudieron ser utilizados como utensilios.

10. Su similitud con las raederas convergentes nos ha desistido de reunirlas en una cuenta común. Igualmente los extremos distales han sido contabilizados como extremos de posibles puntas musterienses en el apartado de fragmentos. 


\begin{tabular}{|c|c|c|}
\hline Tipos & Sílex & Cuarcita \\
\hline 1.- L. levallois & 24 & \\
\hline 3.- P. levallois & 14 & \\
\hline 4.- P. levall. retoc. & 5 & \\
\hline 5.- P. pseudolev. & 3 & \\
\hline 6.- P. musterienses & 101 & \\
\hline 7.- P. muster. alarg. & 3 & \\
\hline 9.- Raed. S. Rectas & 11 & \\
\hline 10.- Raed. S. Convexas & 38 & \\
\hline 11.- Raed. S. Cóncavas & 2 & \\
\hline 13.- Raed. D. Recto-cx. & 3 & \\
\hline 14.- Raed. D. Recto-cv. & 1 & \\
\hline 15.- Raed. D. Bicx. & 17 & \\
\hline 17.- Raed. D. Cv-cx & 3 & \\
\hline 19.- Raed. Converg. Cx. & 4 & \\
\hline 20.- Raed. Converg. Cv. & 1 & \\
\hline 21.- Raed. Desviadas & 4 & \\
\hline 22.- Raed. Transv. Rectas & 2 & \\
\hline 23.- Raed. Transv. Cx. & 2 & \\
\hline 24.- Raed. Transv. Cv. & 3 & \\
\hline 25.- Raed. Cara Plana & 8 & \\
\hline 26.- Raed. Ret. Abrupto & 2 & \\
\hline 30.- Raspadores & 9 & \\
\hline 31.- Raspadores atíp. & 2 & \\
\hline 32.- Buriles & 7 & \\
\hline 34.- Perforadores & 4 & \\
\hline 35.- Perforadores atíp. & 2 & \\
\hline 37.- Cuch. Dorso atíp. & 2 & \\
\hline 38.- Cuch. Dorso natural & 13 & $1+1$ \\
\hline 40.- Truncaduras & 4 & \\
\hline 42.- Muescas & 8 & \\
\hline 43.- Denticulados & 5 & 2 \\
\hline 54.- Muescas en extr. & 1 & \\
\hline 58.- Pedunculados & 1 & \\
\hline 59.- Diversos & 17 & 1 \\
\hline SUBTOTAL & 326 & 5 \\
\hline
\end{tabular}




\section{IV.5.- Análisis de las industrias líticas}

Este capítulo recoge la descripción de las industrias líticas controladas en dos secciones, una dedicada a las piezas completas o casi completas, en las que caben pocas dudas sobre sus distintas adscripciones, y otra dedicada al material fragmentado.

\section{IV.5.1.- Materiales completos}

\section{IV.5.1.1-Lascas no retocadas}

En total se han contabilizado 333 piezas completas, de las que 20 son láminas, y 31 no poseen talón. A ellas hay que unir los 697 fragmentos de lasca que no poseen retoque alguno y de los que 118 presentan talón ${ }^{11}$.

Atendiendo al carácter de las piezas completas, comprobamos que $261(78,38 \%)$ son internas, $47(14,11 \%)$ son semicorticales y $18(5,4 \%)$ son corticales. Debemos tener en cuenta que de las 47 semicorticales, 22 corresponden a cuarcitas y calizas; y que de las 18 corticales, 13 también corresponden a estas materias primas. Esto, unido al alto grado de aprovechamiento que presentan los núcleos de sílex, nos permite inferir que los supuestos nódulos de sílex, o bloques, ya que no hemos podido confirmar cuál fue su fuente, terraza o cantera, fueron objeto de un mayor grado de extracciones, provocado, entendemos, por la calidad del filo por un lado y por la facilidad de talla por otra.

En cuanto a los talones, comprobamos que mayoritariamente poseen talón liso (187-44,5\%), seguidos por los facetados (112-26.7\%). En porcentajes inferiores se hallan los filiformes y suprimidos $(39-9,29 \%)$, corticales $(19-4,5 \%)$ y puntifomes $(5-4,5 \%)$.

\begin{tabular}{|c|c|c|c|}
\hline & Sílex & Caliza & Cuarcita \\
\hline \multicolumn{4}{|c|}{ LASCAS NO RETOCADAS } \\
\hline lascas completas & 229 & 48 & 5 \\
\hline lám. completas & 20 & & \\
\hline 1. completas s/talón & 31 & & \\
\hline 1. rotas c/talón & 117 & & 1 \\
\hline 1. rotas s/talón & 513 & 53 & 13 \\
\hline
\end{tabular}

L.N.R. COMPLETAS. CARÁCTER

$\begin{array}{lr}\text { l. corticales } & 18 \\ \text { l. semicorticales } & 47 \\ \text { l. internas } & 268\end{array}$

\footnotetext{
11. La mayoría de las lascas de caliza aparecen fragmentadas, siendo escasas aquéllas en las que el contorno queda bien delimitado desde su extracción. Igualmente los talones son difíciles de apreciar ya que por la composición de la materia prima suelen estallar, ofreciendo mayoritariamente un talón filiforme las más de las veces. Se han contado cuarenta y ocho completas, de las que trece son corticales, veinte semicorticales y quince internas, cuyos talones son corticales en quince casos, lisos en tres, facetados en dos, filiformes en siete y suprimidos en uno, siendo los demás irreconocibles. Su formato en poco difiere del de las realizadas en sílex. Así mismo se contabilizaron cincuenta y tres fragmentos de lascas. Entre las primeras se cuenta una de dorso natural, cercana a los cuchillos de dorso natural, pero sus dimensiones y la ausencia de melladuras en el filo la han alejado del tipo. En cuanto a las de cuarcita, que suman cinco completas, se cuentan una cortical, dos de dorso natural y otras dos internas, cuyos talones son lisos en cuatro casos, suprimido en otro e indeterminado en el último. Además se han contabilizado trece fragmentos mediales y distales y uno basal de talón liso.
} 


$\begin{array}{lr}\text { L.N.R. TALÓN } & \\ \text { talón cortical } & 19 \\ \text { t. liso } & 187 \\ \text { t. facetado } & 112 \\ \text { t. diedro } & 19 \\ \text { t. puntiforme } & 5 \\ \text { t. filiforme } & 39 \\ \text { t. suprimido } & 39 \\ \text { t. adelgazado } & 275\end{array}$

En cuanto a las dimensiones, pueden deducirse de los siguientes datos estadísticos:

$\begin{array}{lccc} & \text { LONG } & \text { ANCH } & \text { ESP } \\ \text { MEDIA } & 3,33 & 2,54 & 0,77 \\ \text { MEDIANA } & 3,30 & 2,45 & 0,70 \\ \text { MODA } & 3,30 & 1,80 & 0,60 \\ \text { DESV.TIP. } & 1,11 & 0,80 & 0,58\end{array}$

IV.5.1.2.- Restos de talla: esquirlas e informes

En total se han controlado 117 piezas calificadas en este apartado, todas correspondientes a la colección del equipo universitario. Entre ellas distinguimos 85 esquirlas completas de las que un buen número de ellas debieron haber tenido su origen en el proceso del adelgazamiento de las cornisas de los planos de percusión.

\section{IV.5.1.3.- Núcleos}

Sólo se han detectado en la colección recogida por el equipo universitario, entendiendo que la falta de ejemplares en la otra colección es una consecuencia de la recogida selectiva del conjunto. No obstante, como se verá, la presencia de núcleos en el conjunto total es muy escasa, lo que podría denotar un aprovechamiento máximo de la materia prima disponible -consecuencia de ello podría ser las escasas dimensiones de los núcleos controlados-, lo que a su vez, permite suponer una escasez de recursos líticos apropiados, algo que se ha argumentado ya en otras colecciones procedentes de cuevas. La talla en el propio yacimiento debería estar certificada por el relativamente elevado número de piezas no retocadas y el de astillas o esquirlas detectadas. De esto no participan los tres cantos tallados, incluidos entre los núcleos aunque son clásicos ejemplares que documentan sobre la discusión cantos tallados/núcleos ya que su constitución irregular y filo quebrado debería imposibilitar, desde nuestro punto de vista, su inclusión en el grupo de los cantos

12. Se comprobará que el total de estas cantidades no coincide con el anterior, esto se debe a que aquí se han incluido todas las piezas fragmentadas con talón reconocible. 
tallados-herramientas, sin embargo, en un conjunto donde las piezas más grande apenas alcanzan los 100 gramos de peso, estas piezas, cuya masa llega a los 400 gramos, debieron ser los únicos elementos capaces de ser usados como pesados percutores (tanto para la talla como para la fragmentación de huesos), por lo que la discusión sigue viva. Por otro, también debemos incluir en este punto un resto nucleiforme de cuarcita muy cristalina.

Entre los de sílex se han identificado dos núcleos levallois, ambos con talla de carácter centrípeto posterior a la extracción de la lasca preferente; tres centrípetos, uno clásico, con preparación periférica total, otro prácticamente agotado por lo que es imposible determinar si su preparación periférica fue total o parcial, y el tercero presenta una talla irregular. En este mismo apartado debemos citar dos mitades con preparación periférica total -todos ellos prácticamente agotados-; uno con preparación periférica total y una sola extracción en el sentido longitudinal de la pieza; tres con tendencia prismática y huellas de extracciones de lascas laminares extraídas a partir de un solo plano, si bien uno de ellos aparece fragmentado; cuatro con talla irregular presentando huellas de extracciones de lascas; una lasca-núcleo, con posible reutilización como raspador espeso o cepillo; y trece restos nucleiformes.

Igualmente deberían incluirse en este apartado los tres cantos de cuarcita con extracciones en uno de los polos y que debido a la sinuosidad de sus bordes no han sido incluidos entre los cantos tallados.

\section{IV.5.1.4.- Piezas retocadas}

Las piezas retocadas completas (o casi completas, de forma que no hay duda a su adscripción) que pueden adscribirse a los tipos de la lista normativa de F. Bordes (1961) ascienden a 331, de las que 326 fueron realizadas en sílex y 5 en cuarcita. De la citada lista han sido excluidos los cantos tallados, por sistema, ya que en una clasificación de piezas sobre lasca las realizadas sobre canto tergiversarían las anotaciones estadísticas. Además sólo podrían incluirse dos piezas en el apartado de los cantos tallados, dos cantos con talla unifacial en uno de sus extremos, que, aunque formalmente pudieran ser clasificados como choppers, han sido incluidos entre los núcleos por la sinuosidad de su borde.

Además de estas 331, hay que contar con 267 piezas retocadas fragmentadas, la práctica totalidad en sílex, de las que 140 son piezas que no pueden ser adscritas con total seguridad a un tipo si bien su conformación permite deducir un modelo aproximado de la lista normativa y 19 corresponden a fragmentos en los que se puede intuir algún tipo o tipos a los que pueden acercarse. Las 108 restantes sólo pueden ser denominados fragmentos ya que resulta imposible deducir algún tipo en el que incluirlos.

Han utilizado básicamente como soportes lascas internas (294-88,82\%), que poseen generalmente un talón facetado (197-59,52 \%) y, a la vez, también es mayoritariamente adelgazado (234-70,69\%).

Las dimensiones de las piezas completas pueden deducirse de los siguientes datos estadísticos:

$\begin{array}{lccc} & \text { LONG } & \text { ANCH } & \text { ESP } \\ \text { INTERV. } & 9,30 / 230 & 7,51 / 1,40 & 2,20 / 0,45 \\ \text { MEDIA } & 4,46 & 2,96 & 0,95 \\ \text { MEDIANA } & 4,30 & 2,90 & 0,90 \\ \text { MODA } & 4,10 & 3,20 & 0,80 \\ \text { DESV. TIP. } & 1,11 & 0,71 & 0,29\end{array}$




\section{IV.5.1.4.1.- Grupo Levallois:}

El grupo Levallois está formado por 44 piezas completas, repartidas en 25 lascas y 19 puntas, 5 de ellas retocadas, que proporcionan un índice levallois técnico de 18,73, y tipológico de 13,29 . No obstante, hay que recordar que de las 62 piezas levallois contabilizadas para este índice, 17 son sólo de aspecto levallois. Por lo tanto, la industria hay que clasificarla como no levallois. Aún sumando las 6 piezas ( 3 puntas y 3 puntas retocadas) recogidas como posibles en el apartado de fragmentadas, el índice apenas sufriría variación

- Lascas levallois: Suman veinticinco, de las que once son de conformación rectangular y catorce de tendencia ovalar o cuadrada. Los talones son corticales en dos ocasiones, lisos en tres, diedros en cinco, facetados en once, y filiformes en tres, siendo en todos los casos adelgazados. Una de ellas es ligeramente sobrepasada, aunque su conformación general permite incluirla dentro de las típicas. Sus dimensiones máximas se mueven entre 2,90 y $6,60 \mathrm{~cm}$ siendo su media $4,12 \mathrm{~cm}$.

- Puntas levallois: Se cuentan catorce. Sus talones son lisos en un caso, facetados en once, filiformes en uno y desconocido por alteración en una, siendo todos adelgazados. Una de ellas, alargada, presenta el talón parcialmente destruido por un golpe inverso, dejando una muesca levemente indicada.

- Puntas levallois retocadas: Hay cinco, una de las cuales posee su ápice fragmentado y otra es alargada. Todas presentan retoque directo, continuo y cuidado en dos de ellas, casi marginal y parcial en dos e irregular y parcial en el que queda. Todas poseen talones facetados, siendo además adelgazados. Las longitudes de estas piezas junto con las anteriores oscilan entre 3,15 y $8,55 \mathrm{~cm}$ siendo su media $4,72 \mathrm{~cm}$.

\section{IV.5.1.4.2.- Grupo musteriense:}

El grupo musteriense está formado por 208 piezas completas de las que la mitad son puntas musterienses. Esta fortaleza de la representación de puntas musterienses se halla fuertemente matizada si incluimos las piezas fragmentadas con posible adscripción de raedera o punta, ya que entonces la proporción de estas últimas bajaría casi a la tercera parte del total de piezas del grupo. No obstante, no deja de ser relevante esta extraordinaria representación de puntas musterienses, que caracteriza no sólo al grupo sino a toda la industria.

- Puntas pseudolevallois: Son tres y tienen talones facetados. Una de ellas presenta el extremo distal fragmentado. Sus longitudes son 2,70, 3,05 y $3,10 \mathrm{~cm}$.

- Puntas musterienses: Suman 101 y utilizan como soportes 100 lascas internas (una desde una punta levallois con retoque profundo) y una lasca semicortical cuyos talones son lisos en 13 ocasiones, facetados en 69 , diedros en 2 , suprimidos en 13 , rotos en 3 , e irreconocible por alteración en 1 , habiéndose adelgazado 77 de ellos. Del total, 88 se fabricaron con retoque en ambos bordes ( 55 con retoque total, 23 parcial en uno y total en otro, y 14 parcial en los dos) y 13 retocando un sólo borde ( 2 total y 11 parcial). Este retoque fue directo en 91 ocasiones, contabilizándose sólo 3 en las que el retoque fue únicamente inverso, completándose con las piezas que poseen ambos retoques. El modo de retoque es complejo, dándose en una misma pieza varios modos a la ve $z^{13}$. Domina el simple, a menudo unido, aunque de forma parcial, al escaleriforme ( 66 piezas); le siguen las piezas que poseen el simple con partes de abrupto (sólo 18 piezas); el semiabrupto con 6 piezas documentadas y el plano con otras 6 , de las cuales 2 es inverso, perteneciendo los restantes a modos mixtos (el marginal se ha localizado en 8 piezas). Este retoque

13. A veces el carácter de punta musteriense ha sido alcanzado por el leve retoque de uno de los bordes o de los dos que no ha afectado-modificado el soporte original. 
es profundo en 36 ocasiones, poco profundo en 64 y marginal en 1, presentando unas delineaciones convexas en ambos bordes en 70 piezas, cóncavas sólo en 1 , y rectas en 2 , aunque sí se han contabilizado 11 piezas en las que un borde es cóncavo y 18 rectos. El eje morfológico coincide con el técnico en 42 ocasiones, inclinado en 25 y ligeramente inclinado en 33, siendo indeterminado en las restantes. Sus dimensiones máximas oscilan entre 2,70 y $7,10 \mathrm{~cm}$ y su media es de $4,16 \mathrm{~cm}$.

- Puntas musterienses alargadas: Hay tres y están realizadas sobre láminas de talones suprimidos en dos casos y facetado en el tercero. Poseen retoque semiabrupto en un caso, simple, parcialmente semiabrupto, el segundo y simple el tercero, todos directo. Una de ellas ofrece una muesca simple inversa en la mitad basal izquierda, así como el ápice roto. Sus longitudes son 4,05, 5,95 y 6,30 cm respectivamente.

\section{Raederas:}

Las raederas conforman el tipo más frecuente en esta industria. Suman 101 completas, si bien podrían añadirse, de ser ciertas las adscripciones, los 106 fragmentos calificados como tales. Del listado deducimos una mayoría de raederas simples ( 51 completas más 51 posibles fragmentadas) y una fuerte presencia de las dobles ( 24 completas más 51 posibles fragmentadas). Por contra, comprobamos que la representación de las convergentes y de las transversales es muy baja, si bien hay que citar que una buena parte de las raederas dobles se hallan muy cercanas de las convergentes, ya que el retoque se extiende casi al extremo distal.

Han utilizado como soporte mayoritariamente lascas internas $(89-88,12 \%)$, habiéndose detectado sólo 7 láminas. Igualmente los soportes han presentado generalmente talones facetados $(63-62,38 \%)$ y adelgazados $(71-70,30 \%)$.

En general se han fabricado con un retoque cuidado y, mayoritariamente, simple y directo. A veces, el borde de retocado presenta una parte afectada por retoque escalariforme. Sus dimensiones medias ${ }^{14}$ son:

$\begin{array}{lccc} & \text { LONG } & \text { ANCH } & \text { ESP } \\ \text { MEDIA } & 4,88 & 3,21 & 1,00 \\ \text { MEDIANA } & 4,60 & 3,15 & 0,90 \\ \text { MODA } & 4,60 & 3,70 & 0,80 \\ \text { DESV.TIP. } & 1,34 & 0,85 & 0,33\end{array}$

- Raederas simples rectas: Se cuentan once y fueron realizadas sobre una lasca semicortical, y nueve internas (dos con dorso natural y una posible punta levallois con ápice fragmentado), así como en una lámina, también interna. Los talones son facetados en siete casos, lisos en tres y suprimido en uno, siendo ocho adelgazados. Fueron ejecutados mediante retoque simple en nueve casos, marginal en uno y semiabrupto en otro, siendo parcial en dos de los primeros

- Raederas simples convexas: Suman treinta y ocho, de las que siete fueron realizadas sobre lascas semicorticales y veintinueve sobre internas (cuatro con dorso natural y cuatro de aspecto levallois), así como sobre dos láminas. Los talones son corticales en una ocasión, lisos en seis, diedro en uno, facetados en veintidós, suprimidos en dos, rotos en cinco e indeterminado en uno, contándose veintiséis adelgazados. Todas fueron realizadas con retoque simple, excepto una que lo fue con retoque marginal, tres que presentan

14. Hemos comprobado que las raederas convergentes son más grandes que las dobles y éstas a su vez más grandes que las simples. 
retoque escalariforme parcial y una retoque escalariforme total. Se ha detectado retoque semiabrupto parcial en siete ocasiones y semiquina en dos, aunque afectando, este último, de forma parcial al borde de raedera.

- Raederas simples cóncavas: Hay dos y presentan delineación levemente cóncava. Fueron realizadas sobre dos lascas internas, una de aspecto levallois, cuyos talones son facetados. Poseen retoque simple y semiabrupto respectivamente. Una de ellas ofrece en el borde opuesto un retoque marginal que afecta parcialmente a su zona medial.

- Raederas dobles recto-convexas: Son tres y fueron realizadas sobre lascas internas de talones facetados, siendo todos adelgazados. Fueron ejecutadas mediante retoque simple directo en dos de ellas, y casi plano e inverso en la otra

- Raederas dobles recto-cóncavas: Hay una y está realizada sobre una lasca interna de talón diedro. Fue elaborada con retoque simple directo.

- Raederas dobles biconvexas: Hay diecisiete y fueron elaboradas sobre una lasca cortical, otra semicortical y quince internas (tres de aspecto levallois), cuyos talones son corticales en una ocasión, lisos en tres, facetados en diez, suprimidos en dos y rotos en uno, siendo catorce de ellos adelgazados. Once presentan retoque simple directo en ambos bordes (en cuatro casos con retoque escalariforme parcial en uno de los bordes), dos simple, casi plano, inverso en los dos bordes, una retoque simple (escalariforme parcial) en uno de los bordes y en el otro retoque Quina y dos con retoque simple en uno de los bordes y casi marginal en el otro.

- Raederas dobles cóncavo-convexas: Hay tres y se hallan realizadas sobre dos láminas y una lasca de aspecto levallois. Tienen talones facetados, adelgazados en dos ocasiones, poseyendo el borde cóncavo una delineación poco pronunciada. Fueron elaboradas con retoque simple directo, siendo casi marginal en uno y semiabrutpo parcial en otros dos bordes.

- Raederas convergentes convexas: Suman cuatro y se hallan realizadas sobre dos lascas y dos láminas internas de talones cortical, liso y facetados, en dos ocasiones adelgazados. Una de ellas posee retoque simple directo en ambos bordes, otra igual pero parcialmente escalariforme, una tercera parcialmente Quina y la última semiabrupto en uno de los bordes. El retoque es en todos los casos directo, pequeño y cuidado en dos y amplio sobre el que se ha aplicado un retoque más pequeño (escalariforme) en las otras dos.

- Raederas convergentes cóncavas: Sólo hay una y se halla realizada sobre una lasca laminar interna de talón facetado adelgazado. Sólo posee un borde cóncavo, siendo el otro convexo y fue realizada mediante retoque simple directo continuo en ambos bordes.

- Raederas desviadas: Hay cuatro y fueron realizadas sobre una lasca cortical y tres internas, cuyos talones son liso, facetado, suprimido y roto, siendo dos de ellos adelgazados. Tres de ellas pueden considerarse múltiples al presentar tres y cuatro bordes retocados. El retoque con el que han sido elaboradas ha sido el simple, directo en todos los casos excepto en la de cuatro bordes retocados en la que se ha utilizado el inverso para conformar tres de esos bordes.

— Raederas transversales rectas: Hay dos y se hallan elaboradas sobre una lasca semicortical de talón cortical y otra interna de talón suprimido. Ambas poseen retoque simple, directo en un caso e inverso en otro.

- Raederas transversales convexas: Se cuentan dos y se hallan realizadas sobre lascas internas de talones facetados y adelgazados. Una posee retoque simple directo y pequeño, y la otra escalariforme, también directo, estando los bordes inclinados con respecto al eje morfológico de las piezas. 
- Raederas transversales cóncavas: Hay tres y fueron ejecutadas sobre lascas internas, dos de aspecto levallois, de talones facetados y suprimido, adelgazados en dos casos. Presentan retoque simple directo, y bordes de delineación cóncava poco pronunciada.

- Raederas de cara plana: Se cuentan ocho y fueron elaboradas sobre lascas internas (cuatro de aspecto levallois y una con dorso natural) cuyos talones son lisos en tres casos y facetados en los otros cinco, siendo todos adelgazados. En general el retoque es casi plano, en todos los casos cuidado y pequeño, completado con retoque simple directo.

- Raederas de retoque abrupto: Hay dos y se hallan realizadas sobre dos lascas internas, una de ellas espesa, y cuyos talones son facetados y adelgazado en un caso. Se hallan realizados con retoque abrupto, escalariforme en un caso (Quina parcial) y escalariforme parcial en el otro, siendo una transversal.

\section{IV.5.1.4.3.- Grupo Paleolítico Superior}

El grupo paleosuperior se caracteriza por poseer una presencia pobre (índice 9,06), si bien la presencia de cada uno de ellos es similar a excepción de los cuchillos, sólo representados por dos piezas atípicas. Merece la pena hacer mención de la reutilización de las puntas musterienses para la fabricación de buriles, contándose entre ellos el único caso que hemos podido casar con otra pieza, por lo demás perteneciente a colección distinta, lo que documenta, si cabe aún más, la fabricación de útiles en el mismo lugar.

- Raspadores: Se cuentan nueve, de los que tres se hallan fragmentados, faltándole su tercio basal en un caso y mitad basal en los otros dos ${ }^{15}$. Uno está realizado sobre pieza antigua (reutilizado) interna; otro se fabricó a partir de una punta musteriense, y un tercero tiene muchas posibilidades de serlo también. Todos los soportes son internos y los talones identificados son facetados en tres casos, lisos en dos y suprimido en uno, contándose cinco adelgazados. Todos los frentes están situados en el extremo distal y fueron fabricados mediante retoque semiabrupto, en ocho ocasiones y simple en la que queda, todos directo, presentando retoque simple y escalariforme parcial en sus bordes laterales a modo de raedera en siete ocasiones y denticulado en una.

- Raspadores atípicos: Hay dos y están realizados sobre lasca semicortical e interna de talones lisos, adelgazado en una ocasión. El frente es poco destacado, realizado con retoque simple directo irregular. Las dimensiones máximas de los dos tipos de raspadores oscilan entre 3,25 y 6,15 siendo la media de sus longitudes $4,60 \mathrm{~cm}$.

- Buriles: Se cuentan siete de los que uno se realizó sobre lasca semicortical y otro sobre lasca de dorso natural y los restantes sobre lascas internas, siendo sus talones lisos en dos casos, facetados en uno, irreconocible en uno y rotos en los otros tres, adelgazados los tres primeros. Igualmente, tres proceden de puntas musterienses y un cuarto de una pieza apuntada, localizándose los buriles en sus extremos distales en tres ocasiones y en la base en una. Uno es múltiple, dos fueron realizados sobre fractura, uno de ellos antigua raedera, dos pueden ser considerados del tipo busqué, y los otros dos diedros. El realizado sobre la base de una punta musteriense casa con otro fragmento, que completa la pieza, correspondiente a colección diferente. Sus dimensiones oscilan entre 2,80 y $5,20 \mathrm{~cm}$ siendo su media $3,93 \mathrm{~cm}$.

15. Incluidos aquí y no en el apartado de piezas fragmentarias por presentar bien claro el frente de raspador y haber sido realizados sobre sendas láminas. 
- Perforadores: Se cuentan cuatro, todos realizados sobre lascas internas, cuyos talones son facetados y adelgazados en tres casos, faltando en uno por rotura. Excepto uno, de punta muy destacada, que presenta retoque simple inverso, todos fueron realizados mediante retoque simple directo.

- Perforadores atípicos (bec): Hay dos y están realizado sobre lascas internas fragmentadas en su parte basal. Presentan punta lateral poco destacada realizada mediante retoque simple directo en un caso y una muesca ordinaria de retoque directo y retoque simple directo en el borde contiguo. Las longitudes de los dos tipos de perforadores oscilan entre 2,50 y $6,60 \mathrm{~cm}$ y la longitud media es de $4,13 \mathrm{~cm}$.

- Truncaduras: Hay cuatro y se realizaron sobre tres lascas internas y una lámina o lasca laminar, de talones lisos en dos casos (uno de ellos perteneciente a la superficie de una pieza antigua) y facetados en los otros dos, siendo dos adelgazados. Tres de ellas fueron elaboradas mediante retoque semiabrupto inclinado al eje morfológico de la pieza, conformando así piezas apuntadas; y la cuarta posee retoque mixto (semiabrupto y simple). Sus dimensiones máximas oscilan entre $2,30 \mathrm{y} 4 \mathrm{~cm}$ y su media es de $3,50 \mathrm{~cm}$.

- Cuchillos de dorso atípico: Son dos y presentan talones diedro y facetado, adelgazados. Los dorsos corresponden a flancos previos a la extracción de la lasca.

\section{5.1.4.4.- Grupo cuchillos:}

Aunque los cuchillos de dorso se hallan incluidos en la lista normativa de Bordes en el capítulo Paleolítico Superior, parece oportuno hacer un apartado con los cuchillos ya que brillan por su ausencia. Este punto, junto con la presencia modesta, pero firme, de los cuchillos de dorso natural, argumentaría un alejamiento de las industrias avanzadas.

- Cuchillos de dorso natural: Suman catorce, trece de sílex y uno de cuarcita y todos presentan melladuras en su filo (casi marginales, irregulares y parciales en algún caso), opuesto en la casi totalidad de las piezas al dorso, aunque en tres ocasiones éste se halla en plano inclinado con respecto a aquél. Los talones son corticales en dos casos, lisos en seis y facetados en seis, siendo adelgazados seis. Las dimensiones máximas de los dos tipos de cuchillos oscilan entre 3,30 y $8,30 \mathrm{~cm}$ y las medias de sus magnitudes son $4,83 \times 2,71 \times 1,03 \mathrm{~cm}$.

Además, aquí, contabilizamos ocho lascas de dorso natural, una de ellas de cuarcita con características idénticas a las descritas anteriormente a excepción de las melladuras en el filo (contabilizadas entre las lascas no retocadas).

\section{IV.5.1.4.5.- Grupo denticulados:}

Incluimos aquí muescas y denticulados, tipos muy escasos en este conjunto. Esta característica, contraria a lo que se documenta en la mayoría de los conjuntos de similares condiciones (Paleolítico Medio en cueva), no puede ser achacada a la selección de las piezas, ya que debería haber entrado en la colección que no la practicó, parece correlacionarse en cuanto a los denticulados con las industrias del Guadalquivir y Corbones, pero no así en cuanto a las muescas, tipo muy común en todas los conjuntos líticos mediopaleolíticos de graveras.

- Muescas: Se contabilizan ocho, siendo ejecutadas sobre seis lascas, una levallois, y una lámina, internas, y una lasca semicortical, cuyos talones son lisos en dos casos y facetados en los seis restantes, adelgazados seis. Cuatro fueron realizadas mediante retoque inverso y cuatro directo, siendo abrupto en un caso y simple en los demás. Sus dimensiones máximas oscilan entre 4,00 y $5,10 \mathrm{~cm}$ siendo su media $4,44 \mathrm{~cm}$. 
- Muescas en extremo: Hay una aunque su posición ofrece dudas ya que el talón suponemos está suprimido. Fue realizada mediante retoque semiabrupto directo, presentando en un borde lateral otras dos muescas de menores dimensiones casi sucesivas realizadas con retoque simple inverso. Su longitud es de $5,60 \mathrm{~cm}$.

- Denticulados: Hay siete, cinco de sílex y dos de cuarcita y fueron realizados sobre lascas internas de talones lisos en tres ocasiones, facetado en una, filiforme en una y suprimido en la última. Poseen retoque denticulado directo, excepto uno que lo tiene inverso, siendo uno de ellos microdenticulado. Sus longitudes oscilan entre 3 y $4,60 \mathrm{~cm}$ siendo su media $3,74 \mathrm{~cm}$.

\section{IV.5.1.4.6.- Grupo Otros}

En este grupo, relativamente corto en número, hemos incluido los tipos de la lista de Bordes situados entre los números 44 y 63 a excepción del 54, muescas en extremo, que por su naturaleza han sido contabilizadas entre las muescas y los 60 y 61 , choppers y chopping tools, por ser útiles construidos sobre cantos. Como casi ninguno posee unas características amoldables a algunas de las tipologías normativas, han sido clasificados como diversos. Su morfología y tecnología corresponden a las ya conocidas en los tipos anteriores.

- Pedunculados: Hay uno y está realizado sobre un soporte indeterminado interno, de talón suprimido. Posee un retoque abrupto profundo en ambos bordes que ha alterado la morfología del soporte. Tiene un contorno apuntado y el pedúnculo fue obtenido mediante la extracción de una gran lasca directa en el borde izquierdo y una menor, meramente indicada, en el derecho. Su longitud es de $7 \mathrm{~cm}$.

- Diversos: En este tipo contabilizamos dieciocho piezas, una de ellas en cuarcita, entre las que podemos distinguir tres grupos de acuerdo con sus afinidades técnicas. En un primer grupo contamos nueve útiles realizados sobre dos láminas, dos lascas laminares y cinco lascas (dos de aspecto levallois) de talones facetados en seis ocasiones y lisos en tres, adelgazados siete. Presentan retoque marginal parcial, directo en ocho e inverso en uno (podría adaptarse al tipo lascas con retoque sobre cara plana).

El segundo grupo acoge seis piezas, una de ellas en cuarcita, realizadas sobre lascas de talones lisos en tres ocasiones, facetados en dos y suprimido en una, siendo cuatro de ellos adelgazados. Todas poseen retoque simple parcial.

En el tercer grupo se incluyen tres piezas: la primera fue realizada sobre lasca interna de talón suprimido. Tiene contorno apuntado y su borde derecho ofrece una delineación ondulada con retoque cuidado semiabrupto mientras que el izquierdo la delineación es rectilínea, teniendo retoque irregular, casi astillado. Una segunda pieza también de contorno apuntado, realizada sobre lasca interna de talón facetado, presenta retoque abrupto en el borde derecho con delineación ondulada. La tercera fue elaborada sobre una lasca semicortical de talón suprimido por el retoque, simple y profundo, que afecta a la mitad basal, dándole a ésta una conformación apuntada. Sus dimensiones máximas oscilan entre 2,90 y $5,40 \mathrm{~cm}$ siendo la media de sus dimensiones $4,02 \times 2,67 \times 0,87 \mathrm{~cm}$.

\section{5.1.5.- Varios}

Raedera sobre resto nucleiforme presentando un borde arqueado y realizada mediante retoque semiabrupto escalariforme. 


\section{IV.5.1.6.- Material fragmentado}

Como ya hemos comentado, este material ha sido dividido, a su vez, en tres subgrupos, uno donde incluimos aquellas piezas que pueden ser clasificadas en determinados tipos con alto margen de fiabilidad (grupo A), otro cuya característica esencial es el presentar uno o dos bordes con retoque continuo, por lo que, en principio, sólo podrían ser aceptados en el grupo de las raederas (grupo B), y un tercer grupo que sólo ofrece algún retoque parcial $o$, simplemente, apunta el retoque, que puede ser continuo o no (grupo C).

\section{IV.5.1.6.1.- Grupo A:}

En general, estas piezas fragmentadas, poseen escasas diferencias observables con los ejemplares completos tanto desde el punto de vista morfológico como técnico.

- Puntas levallois: Se cuentan una mitad basal y dos a las que sólo les falta el extremo. Poseen talones facetados y una puede ser considerada ancha.

- Puntas levallois retocadas: Admitir como tales piezas a las que le falta el extremo distal es, como ya hemos mencionado, harto aventurado, no obstante, ofrecen la clásica conformación en su mitad basal y sus bordes laterales poseen una orientación convergente bien patente. Se cuentan tres, y poseen talones facetados. Dos de ellas tienen retoque casi marginal, siendo irregular casi denticulado en uno de sus bordes y las otras dos ofrecen retoque plano inverso cuidado en ambos bordes, por lo que, en caso de que definitivamente pudieran incluirse entre las levallois, se tratarían de dos puntas de Soyons.

- Puntas musterienses: Se cuentan veinticinco piezas fragmentadas con características muy cercanas a las de las puntas musterienses. La seguridad de su adscripción es mayor en los 14 fragmentos distales, todos bien apuntados y, excepto uno, con retoque en ambos bordes. En cambio, en los fragmentos basales esta seguridad disminuye fuertemente dado que sus características pueden confundirse con las de las raederas, dobles o convergentes, sin embargo, la fuerte tendencia triangular y a converger ambos lados retocados, amén de la fuerte presencia de puntas musterienses verdaderas, nos han inclinado a incluirlas como posibles puntas. Utilizaron como soportes mayoritariamente lascas internas (23), con talones facetados (10). El retoque afectó a ambos bordes en 24 ocasiones, poco profundo (21) siendo directo en 22 casos y simple (con escalariforme parcial) en 20 ejemplares. La delineación es mayoritariamente convexa en ambos bordes ( 24 casos).

- Raederas simples rectas: Se cuentan cuatro, de las que dos son fragmentos a los que parece faltarle el tercio distal. Utilizaron como soporte lasca y lámina, o al menos lasca laminar, internas (la última con dorso natural), cuyos talones son facetados, siendo uno adelgazado. Presentan retoque simple, uno de ellos escalariforme parcial. Su delineación tiende a cierta convexidad. Las otras dos son fragmentos mediales realizados sobre lasca interna y lasca, posiblemente, laminar, semicortical. El primero posee retoque simple casi marginal, y el segundo escalariforme cuidado presentando delineación levemente cóncava.

- Raederas simples convexas: Se cuentan cuarenta fragmentos. Para su análisis ha sido divididos en trece fragmentos basales y diez a los que les faltan el tercio distal que ha utilizado como soportes (de acuerdo con el fragmento) una lasca cortical, dos semicorticales, doce internas, dos láminas y seis lascas laminares o láminas, internas, también, cuyos talones son lisos en cinco casos, facetados en dieciséis, puntiformes en uno y suprimidos en uno, siendo doce adelgazados. El retoque es simple mayoritariamente (17 piezas), contándose tres casos de retoque escalariforme. Otros cinco fragmentos son mediales que utilizaron 
como soportes cuatro lascas internas y una semicortical. Poseen retoque simple en un caso y escalariforme en otro. Los doce fragmentos restantes son distales y se ejecutaron sobre seis lascas, y seis láminas o lascas laminares, todas internas. Poseen retoque simple, escalariforme parcial en tres casos y casi marginal dos, delineación irregular en una ocasión y retoque denticulado en el borde opuesto en otra de las piezas.

- Raederas simples cóncavas: Se contabilizan siete, un tercio y una mitad basal así como cinco fragmentos distales, tres mitades, un tercio y otro al que sólo le falta el tercio basal. Fueron realizados sobre cinco lascas internas y dos láminas o lascas laminares, una interna con dorso natural y otra semicortical (ésta última con dorso natural), de talones liso y facetado respectivamente. Presentan retoque simple, en dos casos casi marginal, con delineación levemente cóncava uno de ellos, y escalariforme parcial en otro.

- Raederas de cara plana: En total suman cuatro, un fragmento basal, dos fragmentos a los que le faltan el extremo distal y una mitad distal. Realizadas sobre una lasca semicortical, y dos lascas y una lámina (o lasca laminar) internas. Los talones son facetado, lisos y suprimido. El retoque es simple (casi plano) en tres y plano en uno, cuidado y continuo.

- Raederas dobles: En este apartado hemos incluido un total de cincuenta y una piezas fragmentadas con características propias de raederas dobles, es decir con los dos bordes laterales con retoque continuo, parcial o total. Entre ellas hemos podido clasificar de acuerdo con la lista normativa dieciséis piezas, pero el resto (treinta y cinco) han de ser admitidas en el concepto genérico de raedera doble, sin especificar si es convergente o no ya que falta su extremo distal.

De estas treinta y cinco piezas que responden al concepto genérico de raedera doble se han catalogado veintisiete fragmentos basales comprendidos entre un tercio y dos tercios de la pieza. Entre sus soportes encontramos trece láminas (entendiendo que el fragmento que falta se conforma de acuerdo con las características del que analizamos), diez lascas laminares o láminas, y cuatro lascas, cuyos talones son lisos en diez ocasiones, facetados en once, diedros en una, puntiformes en una, suprimidos en tres y roto en una, siendo dieciséis adelgazados. Excepto dos ejemplares que ofrecen delineación cóncavoconvexa, todos los demás la tienen biconvexa. El retoque predominante es el simple contándose cinco piezas que ofrecen retoque escalariforme de forma parcial, dos escalariforme total en uno de sus bordes, así como una con retoque abrupto en uno de sus bordes.

Las ocho restantes son fragmentos mediales de raederas dobles sobre lascas o láminas. En un caso ofrece una delineación recto-convexa y en otro la delineación es biconvexa, aunque dado su espesor, su retoque elevado y su contorno, no podemos desechar la idea que pudiera tratarse de una limace. Los seis que restan son tan pequeños que es aventurado decir cual sería su delineación.

- Raederas dobles recto-convexas: Hay tres, correspondientes a una mitad distal y dos tercios distales de lascas laminares o láminas internas. Dos de ellas presentan retoque simple directo en ambos bordes y la tercera retoque semiabrupto en el borde izquierdo y simple casi marginal en el derecho, ambos directos.

- Raederas dobles biconvexas: Tres fragmentos distales de lasca y, posiblemente, láminas internas. Poseen retoque simple, casi marginal en uno de los bordes de una de ellas y escalariforme parcial en otro.

- Raederas dobles cóncavo-convexas: Tres mitades distales de lasca laminar o lámina y lámina internas. Presentan retoque simple directo en ambos bordes.

- Raederas convergentes: En total se contabilizan siete fragmentos distales y un fragmento lateral con retoque generalizado en ambos bordes los primeros y en el borde derecho el segundo, presentando el borde izquierdo degradado por alteración mecánica. Todos, excepto uno que tiene en uno de sus bordes un retoque semiabrupto, presentan retoque simple y escalariforme parcial. Todos parecen presentar una delineación biconvexa excepto una que lo tiene cóncavo-convexa. 
- Perforadores: Hay uno y se halla realizado sobre lasca interna de talón liso adelgazado. Su punta se halla fragmentada aunque debió ser muy destacada, quedando su parte inferior que presenta retoque simple en uno de los bordes y semiabrupto en el opuesto.

- Denticulados: Hay dos, realizados sobre lasca y lasca laminar internas con fractura lateral y distal respectivamente y talones suprimido y facetado. Poseen un borde denticulado mediante retoque simple, la primera, y semiabrupto la segunda, ambos directos, en bordes basal y distal.

\section{IV.5.1.6.2.- Grupo B}

En este grupo, cuya característica esencial es la de presentar uno o dos bordes con retoque continuo, por lo que sólo podrían ser aceptados en el grupo de las raederas, incluimos, como ya hemos comentado, aquellas piezas fragmentadas cuya adscripción tipológica resulta altamente problemática y debe ser tratada con todas las reservas.

- Punta levallois: Hay una a la que le falta el tercio distal y presenta talón facetado

- Piezas apuntadas: Once fragmentos distales (sus características morfológicas -anchas o excesivamente alargadas- impiden clasificarla como puntas musterienses) de piezas apuntadas, nueve de las cuales corresponden al menos a la mitad distal, presentando todos el extremo distal apuntado conformado por retoque en ambos bordes. El retoque es directo y simple salvo en un caso, correspondiente a una lámina o lasca laminar espesa, que es escalariforme y abrupto, y en otro en que es escalariforme y semiabrupto, siendo en los demás simple. En todos los casos la delineación es convexa.

- Fragmentos basales de lascas laminares o láminas con muesca (pedunculado unilateral): Son siete y están realizados sobre una lámina y seis soportes indefinidos, todos ellos internos, excepto uno que es semicortical, de talones facetados. Todos presentan una muesca basal, en un caso muy amplia, obtenida en seis ocasiones por un sólo golpe -dos directos, cuatro inversos-, teniendo tres de ellas retoque posterior, y en una por retoque directo. Tres de ellas poseen retoque simple continuo en uno de sus bordes, una directo y dos inverso, denticulado una.

\section{IV.5.1.6.3.- Grupo C:}

En este grupo hemos incluido fragmentos de pequeñas dimensiones con uno o dos bordes retocados o con sólo retoque parcial y/o irregular. Se cuentan 76 fragmentos mediales y distales y 32 fragmentos basales ( 4 talón liso y 25 facetados, 3 suprimidos, 2 rotos, 14 adelgazados) con retoque poco cuidado e irregular directo en 101 , inverso en 6 , y alternante en 1 , contándose 27 piezas que tienen retoque continuo cuidado, uno abrupto y siete continuo marginal y la mitad basal de una lámina con retoque marginal en el borde derecho.

\section{V.- DISCUSIÓN}

Nos encontramos ante un conjunto lítico que, a pesar de ser incompleto y descontextualizado, es muy homogéneo. Como hemos podido comprobar, el análisis de las piezas nos ha permitido conocer que sus características morfológicas y tecnológicas dejan poca cabida a la variabilidad ${ }^{16}$. Las referencias estadísticas

16. Recuérdese que en las cuevas de Horá y Carigüela, donde los estudios han sido muy rigurosos, las diferencias entre las industrias de los diversos niveles mediopaleolíticos, en Carigüela más de treinta, no son significativas. 
permiten comprobar que la morfología del conjunto se halla dentro de unos parámetros que podemos considerar medios/pequeños, siendo escasas las piezas que se hallan por debajo de la media $(3,90 \mathrm{~cm}$ de dimensión máxima) y aún más las que se hallan por encima. Igualmente, hemos comprobado también que, desde el punto de vista técnico, tanto los soportes como los retoques y modos de fabricación presentan fuertes analogías, referenciados en unos soportes generalmente no corticales y delgados (espesor medio: $0,89 \mathrm{~cm}$ ) con contornos de tendencia triangular -apuntados o bordes laterales con tendencia a converger-, talones facetados, en buena medida adelgazados, procedentes de una talla que en general podemos denominar paralevallois, de ángulos de ataque muy planos ( $90^{\circ}$ o cercano) y estigmas de talla de tendencia centrípeta cercana a la levallois ${ }^{17}$. Igualmente, se constata fundamentalmente un modo de retoque simple, poco profundo -con excepciones, especialmente en las puntas donde el retoque profundo está muy presente-, cuidadó y pequeño -con presencia del lamelar-, a veces escalariforme - generalmente parcial, pocas veces completo-, que afecta a dos de los bordes de tendencia convergente, si bien es verdad que hay una estimable proporción de piezas, especialmente raederas, en las que el retoque de uno de los bordes presenta un tratamiento distinto al otro (cuidado-no cuidado; profundo-marginal,...).

Por otro lado, constatamos cómo las industrias se concentran alrededor del grupo musteriense, donde las raederas y puntas musterienses poseen una representación más que notable, apoyado también por la escasa variabilidad técnica que existe en la obtención de estos dos tipos de útiles.

Pero lo que caracteriza a esta industria es el alto número de puntas musterienses (ciento una, que unidas a las veinticinco posibles sumarían ciento veintiséis, cantidad que aún podría elevarse si se les uniesen todas aquellas piezas rotas apuntadas y cuya adscripción definitiva aún queda en el aire). A pesar de que el conjunto no ha sido localizado en contexto y que, además, corresponde en buen grado a una posible selección, esta cualidad aún sigue definiendo el conjunto, pues no conocemos ningún yacimiento que haya proporcionado tal número de puntas en relación a la cantidad de sedimento removido. Por otro lado no debemos olvidar el carácter apuntado que tiene la industria desde un punto de vista global.

Poco sabemos acerca del depósito en el que se encontraba, y no dudamos de que en él pudieran detectarse variados estratos, pero la homogeneidad de la industria y la correlación temporal que parecen demostrar los restos paleontológicos con ella parecen apuntar a un espacio cultural único o de características muy similares situado cronológicamente en el Pleistoceno Superior, hipótesis ésta que no es desmentida por los restos paleontológicos analizados. Esta consideración es del todo especulativa, pero posible, y pretende asentarse en algunos otros casos demostrados, entre los que destaca para nuestra área geográfica el de Carigüela (Granada), donde los treinta y dos niveles musterienses (Vega Toscano 1989) han ofrecido industrias de características muy homogéneas, con diferencias que no pasan de ser meras matizaciones, siendo calificada bajo el epígrafe de Musteriense (Vega Toscano 2000)

\section{V.1.- La industria de la cueva de Santisteban en el marco del Bajo Guadalquivir}

El Bajo Guadalquivir ha proporcionado numerosas colecciones de industrias líticas, tanto del Paleolítico Inferior como Medio; si bien ofrecen un denominador común: son industrias asociadas a graveras, y hasta ahora todas en posición secundaria ${ }^{18}$. Esta misma asociación a graveras determina que la materia prima

17. Técnicamente comprobamos que es una industria no levallois, aunque con aspecto de este tipo de talla. Como ya hemos citado, las piezas que pueden clasificarse como levallois preferenciales son pocas, no así las de aspecto de esta talla, cuyo número si es elevado.

18. Hay algunos yacimientos que, situados en niveles de lacustres y con piezas de aristas vivas, permiten mantener la esperanza de que se hallen in situ: caso de Muharra (Caro 1999). 
sea la de los propios depósitos, mayoritariamente cuarcita ${ }^{19}$. El uso mayoritario de cuarcita ha determinado la presencia mantenida de macropiezas (especialmente bifaces y hendedores, en menor medida o casi ausentes, los triedros), así como una menor presencia de los grupos 1 y 3 , y mayores proporciones de muescas. De no ser así, tendríamos que proponer una diferenciación dura de utillaje entre los pobladores de las sierras y los del valle, cosa harto improbable, máxime cuando tenemos bien demostrado ya desde el Achelense (Arnáiz y Mediavilla 1986; Fernández Caro 1998) que en los mismos conjuntos líticos encontramos el uso de técnicas diferentes según la materia prima usada.

La relación más sugerente, en orden a la proximidad geográfica, podemos establecerla con la industria en sílex de Tarazona II, que no con la realizada en cuarcita, de características bien diferentes, como ya se ha puesto de manifiesto. (Díaz del Olmo, Vallespí y Baena 1992). Este yacimiento ha sido desde fines de los años ochenta, en que se descubrió, el punto de referencia en el sostenimiento de una hipótesis de trabajo en la que se situaba el Paleolítico Medio de graveras como una prolongación del Achelense sobre el que había impactado la llegada de las nuevas tecnologías musterienses. La permanencia del Achelense se manifestaba en la fuerte presencia de macroindustrias (todas en cuarcita), y la tecnología musteriense en la presencia de una notable relación del grupo musteriense, tanto de raederas como de puntas (todas en sílex), de gran calidad técnica, y que sus autores presentaban como el enlace con las industrias musterienses de las cuevas de los sistemas béticos, si bien hay que hacer notar que su posición en la trama geomorfológica no se halla bien definida, permitiendo, en contrapartida, la hipótesis de que el conjunto tenga un procedencia dispar, defendida precisamente en esa dicotomía: macroindustria en cuarcita, puntas y raederas en sílex ${ }^{20}$.

Por lo que hemos podido ver de ella y se ha escrito, las industrias de sílex se comportan morfológica y técnicamente como las de Santisteban, si bien creo que aquéllas poseen unas medidas mayores que éstas. Las únicas estadísticas conocidas son las realizadas por J.A. Caro en su tesis doctoral, pero como él mismo expone, se trata de un estudio provisional, donde, además, el estudio de las industrias de sílex y cuarcita se hacen conjuntamente, no por separado, lo cual invalida cualquier tipo de comparación.

Lo que no cabe duda es que de aceptarse la posibilidad de que todas las industrias de Tarazona II correspondan a un mismo conjunto industrial, obtendríamos una referencia clara de un momento poco conocido hasta el momento y del que se ha especulado mucho. Con él comprobaríamos que el paso del Pleistoceno Medio al Superior correspondería a un período de crisis donde los utillajes estarían formados por piezas con fuertes referencias achelenses a la vez que por otras en las que el grupo musteriense iría adquiriendo una fuerza hasta ahora desconocida. Lo que quedaría por explicar es porqué el uso diferenciado de materia prima según se trate de uno u otro bloque de herramientas.

De cualquier forma, la existencia del conjunto de industrias líticas correspondiente a la paleocavidad que aquí presentamos, y que participa de los ambientes de sierra y campiña, pone de manifiestoque la industria musteriense clásica se halla bien presente a escasos metros de los ambientes de gravera ${ }^{21}$ donde hasta el momento las industrias pertenecientes, o asociadas, a los aluvionamientos del Pleistoceno Superior y clasificadas como Paleolítico Medio, ofrecen una tradición achelense innegable, con presencia sostenida de bifaces, especialmente.

19. La evolución del uso de materias primas/tecnologías ofrecida por Díaz del Olmo y Vallespí (1992), y mantenida por J.A. Caro (1999), según la cual conforme avanzamos en el Pleistoceno los depósitos cargan más sílex y la industria ofrece mayor número de piezas en esta materia, no ha podido ser confirmada por el autor en los depósitos que afloran junto al curso bajo del río Corbones, el cual se desarrolla disectando precisamente las terrazas 6 a 14 del Guadalquivir.

20. No desechamos la posibilidad de que esta industria corresponda a momentos del Pleistoceno Superior, de acuerdo con el nivel geomorfológico en el que fue hallada. Se hallaría en la línea de las industrias halladas en los bordes de la cuenca del Corbones sobre depósitos del Guadalquivir (Fernández Caro 2002), si bien con una potente representación de piezas en sílex.

21. Al aire libre y en relación con los depósitos sedimentarios del Guadalquivir y ríos tributarios -Corbones y Genil-en sus tramos bajos, que disectan las formaciones del mismo río colector, y cuyas cargas son esencialmente de cantos de cuarcita. 
Ello presenta nuevas interrogantes en el estudio del Paleolítico Medio del Valle del Guadalquivir, que, posiblemente, la excavación de un yacimiento en posición primaria permitiría adentrarse en su solución. El conjunto de nueve yacimientos en superficie estudiados sobre las terrazas medias y altas del Guadalquivir (Fernández Caro 2002), de características físicas muy cercanas entre sí (industria muy concentrada en límites muy semejantes), ofrecen una similitud (morfológica, tecnológica y tipológica) tal que permite apuntar con cierta confianza hacia un modelo de asentamiento y utillaje tecnológico, que, precisamente por sus características, permite ser insertado en el Paleolítico Medio no clásico, fluvial en la pluma de E. Vallespí.

\section{V.2.- La industria de la cueva de Santisteban en el marco del sur peninsular}

Una vez más debemos apuntar a los dos grandes focos de estudio del sur peninsular, Horá y Carigüela (Píñar), a los que habrá que añadir el de Gibraltar, no sólo por las publicaciones añejas, en el sentido literal de la palabra, sino por las nuevas investigaciones llevadas a cabo por el equipo de Finlayson y Giles. Si la primera es más interesante para los niveles más modernos del Pleistoceno Medio y antiguos del Superior, los de Carigüela estudiados hasta ahora ofrecen un abanico temporal que abarca los momentos finales del Pleistoceno Medio y todo el Superior. Las industrias halladas en Santisteban son del todo comparables a las analizadas en Carigüela, si bien sus proporciones son diferentes en base a la concentración de puntas de la cueva moronense, permitiendo llevar hasta el mismo borde de la Depresión del Guadalquivir unos modos de producción musterienses que hasta ahora se han revelado esquivos en el llano, a la vez que tiende un puente a Tarazona II por donde conectar con el mundo de las cuevas del Sistema Bético, que no es más que una continuación del musteriense clásico mediterráneo, en términos geográficos, y en el que se integran también los yacimientos de Gibraltar y su entorno.

\section{V.3.- Valoración histórica}

Tecnológicamente asociada al musteriense, la industria de Santisteban no ha ofrecido ningún elemento que permita intuir algún nivel del Paleolítico Superior, por lo que es apropiado asociar esta industria sólo a neandertales de acuerdo con la corriente actualmente aceptada de que los hombres modernos fueron los responsables de las industrias paleosuperiore ${ }^{22}$. Esta ubicación tan cercana al Bajo Guadalquivir asociada como ya hemos comentado al mundo de las cuevas del dominio Bético, permite intuir una explotación del llano por estos neandertales, quedándonos la interrogante de si comparten el espacio con los responsables de los conjuntos industriales "de las graveras" o por el contrario se hallan en franca competencia con ellos.

Además nos ha sido vedada la posibilidad de conocer si el asentamiento en la cueva fue estacional o duradero, lo cual, con el referente de Zafarraya, hubiese abundado en el aspecto de la depredación estacional, de acuerdo con el estudio de los restos en los que se conservan marcas de descarnamiento que, por lo demás, sí ha demostrado la consumición in situ.

La cercanía de las industrias de sílex de Tarazona II, en caso de demostrarse una adscripción mesopaleolítica, permite pensar en una población musteriense clásica si no en el propio Valle del Guadalquivir, sí en su borde más meridional, que se enfrenta radicalmente a las conocidas hasta ahora, donde la cuarcita es mayoritaria, y la tecnología diferenciada.

22. Conocemos industrias superopaleolíticas (chatelperronenses) asociadas a restos neandertales pero no industrias musterienses asociadas a hombres modernos. 


\section{4.- Conclusión}

En definitiva, este yacimiento, a pesar de las limitaciones de su registro, ofrece por un lado la constatación de unas industrias musterienses clásicas en el Bajo Guadalquivir, lo cual se hallaba sólo intuido a partir de determinados conjuntos muy limitados y de las industrias de sílex (minoritarias) en el seno de conjuntos realizados mayoritariamente en cuarcita, propios de lo que se ha dado en llamar "Paleolítico Medio de graveras"; y por otro, un conjunto de claro carácter apuntado, que, de entrada, debemos asociarlo a una posible actividad cazadora. Así mismo, los restos óseos con muestras de acción antrópica no dejan ser meros testimonios de la propia acción humana que garantizan el uso de la paleocavidad como asentamiento, seguramente estacional, de acuerdo con las hipótesis de trabajo de los responsables de las excavaciones en Cariguiela (Vega 2000) y Zafarraya (Barroso 2000).

\section{BIBLIOGRAFÍA}

ARNÁIZ, M.A. y MEDIAVILA, O. (1986): "Villarmero: Un yacimiento 'premusteriense' al aire libre en la zona oriental de la Meseta", Numantia. Investigaciones Arqueológicas en Castilla y León II: 7-31. BARROSO, C. (2000): "En Zafarraya", Primeuro. Los primeros habitantes de Europa. El Ideal de Granada, 19 de Noviembre de 2000.

BOTELLA, M.C.; MARTÍNEZ, C. y CÁRDENAS, F.J. (1986): "Industria musteriense y achelense en Cueva Horá (Darro, Granada)", Homenaje a Luis Siret. Consejería de Cultura de la Junta de Andalucía.

CARO GÓMEZ, J.A. (1999): "Yacimientos e industrias achelenses en las terrazas fluviales de la Depresión del Guadalquivir (Andalucía, España)". Inédita.

CRUZ AUÑÓN, M.R.; MORENO ALONSO, E. y CÁCERES MISA,P. (1993a): "Registros de la expresión poblacional durante el III milenio", SPAL 1: 125-150. Universidad de Sevilla.

CRUZ AUÑÓN, M.R.; MORENO ALONSO, E. y CÁCERES MISA, P. (1993b): "Estudio del hábitat calcolítico en el pié de sierra del Bajo Valle del Guadalquivir", Investigaciones Arqueológicas en Andalucía. 1985-92. Proyectos: 373-382. Huelva.

CRUZ AUÑÓN, M.R. y JIMÉNEZ BARRIENTOS, J.C. (1996): "El Cerro de Santisteban: Aplicación de un modelo de urgencia para el conocimiento y protección de un yacimiento prehistórico en Morón de la Frontera", MAUROR: 1-12.

CRUZ AUÑÓN BRIONES, M.R. y DUARTE, F. (2001): "Morón de la Frontera hace 4.000 años o más", Actas de las IV Jornadas de Temas Moronenses: 13-27. Sevilla.

DÍAZ DEL OLMO, F.; VALLESPÍ, E. y BAENA, R. (1992): "Bajo Guadalquivir y afluentes secundarios: Terrazas fluviales y secuencia paleolítica (trabajos 1990)", AAA 1990 II: 35-39.

FERNÁNDEZ CARO, J.J.(1998): “Las industrias líticas paleolíticas del Bajo Guadalquivir: Río Corbones". Tesis doctoral inédita.

FERNÁNDEZ CARO, J.J; BAENA ESCUDERO, R. y GUERRERO AMADOR, I. (1999): “Poblamiento e industrias líticas a orillas del río Corbones. La Puebla de Cazalla (Sevilla)”, Cuadernos de Historia 2. Ayuntamiento de La Puebla de Cazalla.

FERNÁNDEZ CARO, JJ. (2000): "El Paleolítico Medio de medios fluviales: Yacimientos en superficie de la cuenca del Corbones, afluente del Guadalquivir", SPAL 9: 225-244.

FINLAYSON, C. (1999): "Late Pleistocene Human Occupations of the Iberian Peninsula", Journal of Iberian Archaeology 1: 59-68. 
FINLAYSON, C. y FINLAYSON, G. (2000): “Cambio climático, vegetación y fauna del Sistema Bético. Consideraciones sobre sus efectos en la ocupación humana en la Serranía de Ronda durante los estudios isotópicos 3 y 2", Neanderthals on the Edge. Edited by Stringer, Barton and Finalyson. Oxbow Books.

FINLAYSON, C. y GILES, F. (2000): "The Southern Iberian Peninsula in the Late Pleistocene: Geography, Ecology and Human Occupation", Neanderthals on the Edge: 139-153. Edited by Stringer, Barton and Finalyson. Oxbow Books.

FINLAYSON, C. et allii (2000): "Human occupation of Gibraltar during oxigen isotope stages 2 and 3 and a comment on the late survival of neanderthals in the southern Iberian Peninsula", Separata das Actas do $3^{\circ}$ Congreso de Arqueología Peninsular Volumen II Paleolítico da Peninsula Iberica: 277 y ss. ADECAP 2000. Porto.

FINLAYSON, J.C.; BARTON, R.N.E. y STRINGER, C.B. (2001): "The Gibraltar Neanderthals and their extinction", en Zilhao, J.; Aubry, T. y Carvalho, A. (Eds), Les premières hommes modernes de la Péninsule Ibérique. Actes du Colloque de la Comisión VIII de l'UISPP. Trabalhos de Arqueología 17: 117-122.

VALLESPÍ, E. y DÍAZ DEL OLMO, F. (1990): "Industrias de cuarcita y comienzos del empleo de sílex en la secuencia del Paleolítico Inferior y Medio del Bajo Guadalquivir", Quarzite and other non flint lithic material in the Iberian Palaeolithic. B.A.R. Univ. of Oxford.

VALLESPÍ, E. (1994): "EL Bajo Guadalquivir en el Paleolítico Inferior y Medio", Museo y Centro de Investigación de Altamira. Monografias 17: 13-16.

VEGA TOSCANO, L.G. (1988): “El Paleolítico Medio del Sureste Español y Andalucía Occidental”, Facultad de Geografía e Historia. Departamento de Prehistoria. Universidad Complutense. Madrid.

VEGA TOSCANO L.G. (1989): "Investigaciones en torno al yacimiento de la cueva de Carigüela (Píñar, Granada)", Raña 7.

VEGA TOSCANO, L.G.; HOYOS, M.; RUIZ-BUSTOS, A. y LAVILLE, H. (1988): "La sequénce de la grotte de la Carihuela (Piñar, Grenade)", Chronostratigraphie et Paléoécologie du Pléistocène supérieur au Sud de la Péninsule Ibérique. L'Homme de Néanderthal, vol. 2: 169-180. L'Environment, Liège.

VEGA TOSCANO, L.G. (2000): “Los últimos neandertales", Primeuro. Primeros habitantes de Europa. El Ideal de Granada, 19-11-2000.

VERA REINA, M. y FERNÁNDEZ RUIZ (1991): "La prehistoria en Morón de la Frontera", Desde la frontera 1: 1-45. 

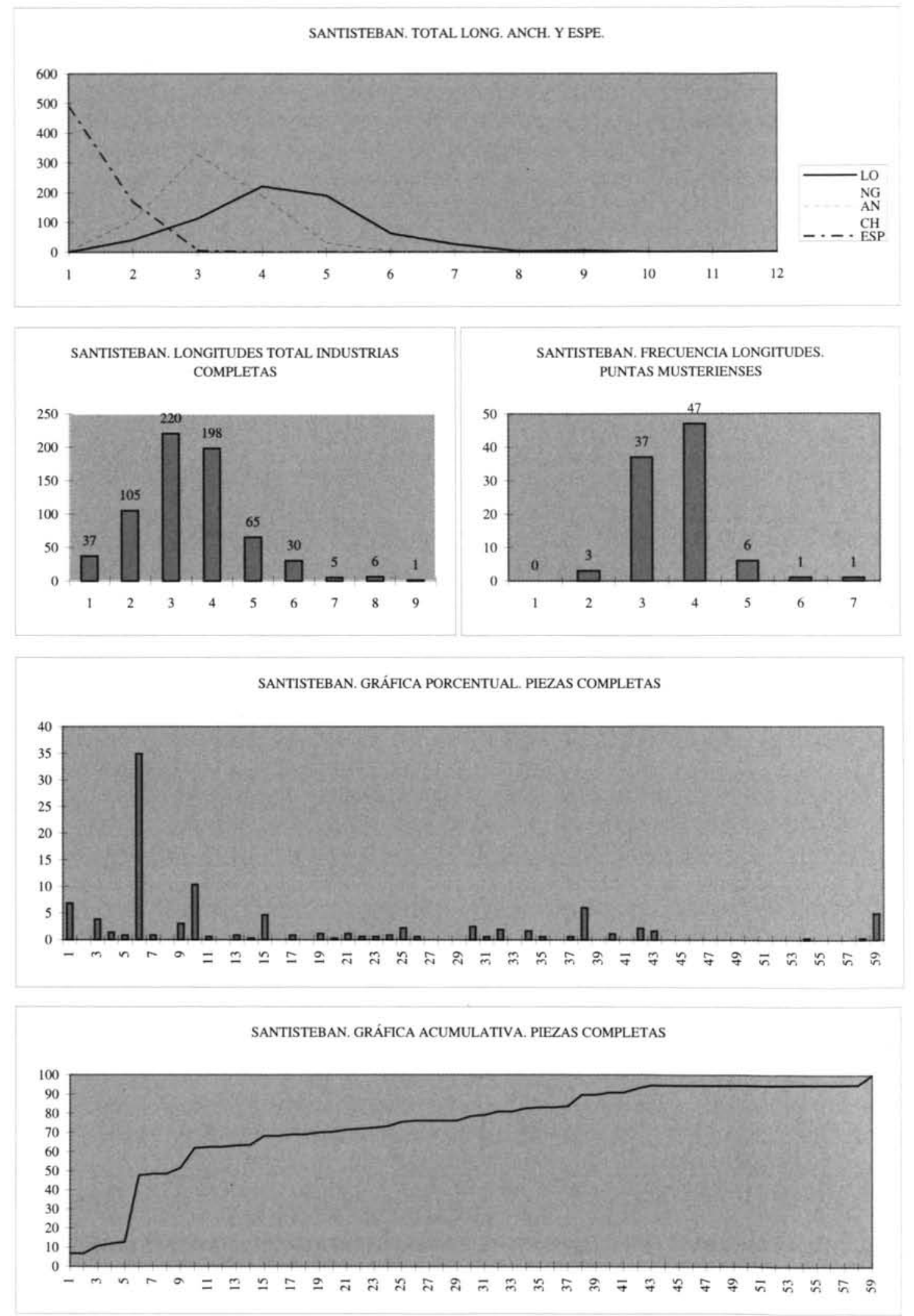

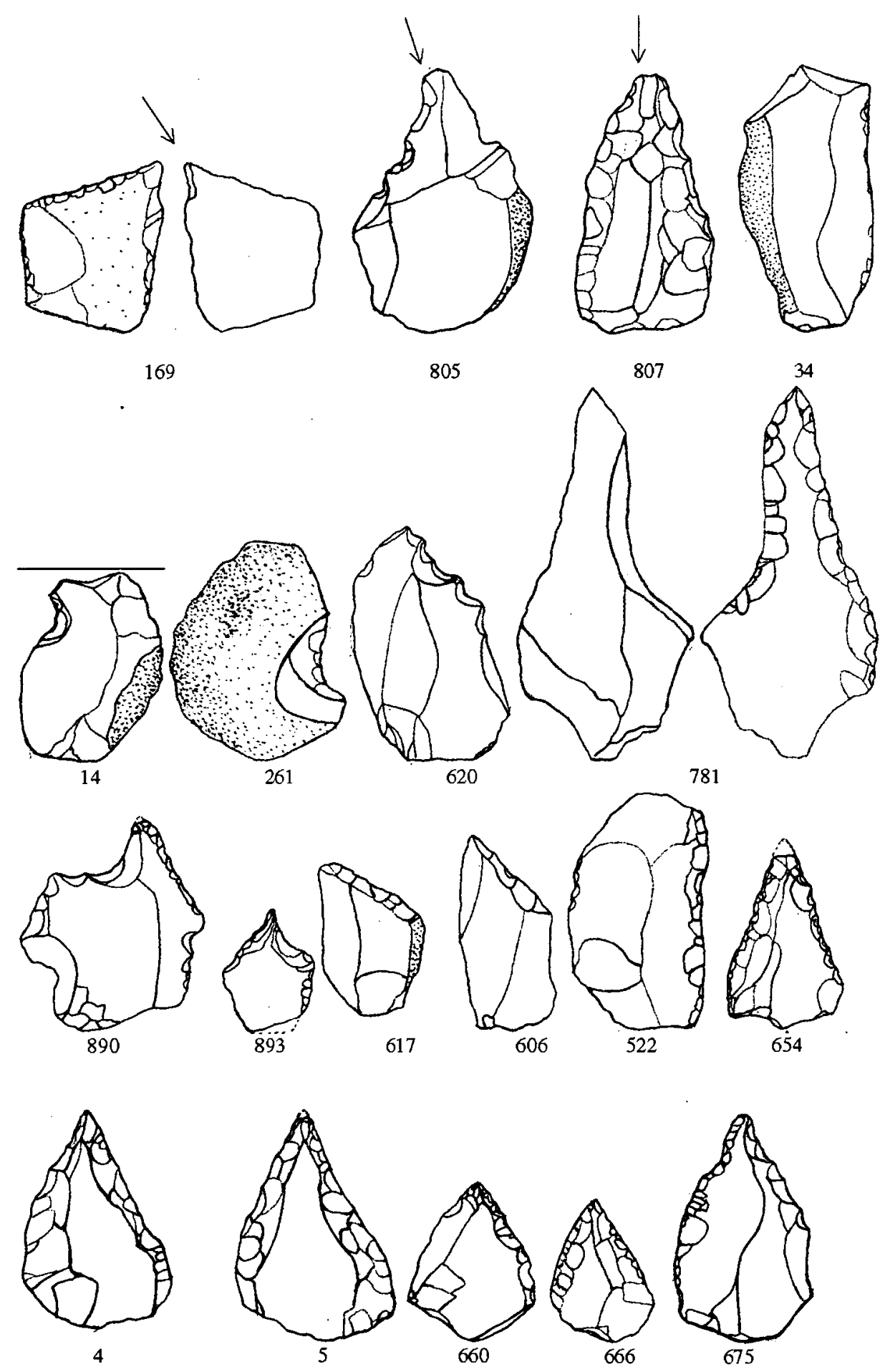

Lámina 1.- Buriles (169, 805 y 807), cuchillos de dorso natural (34), muescas (14 y 261), denticulado (620), perforadores $(781,890$ y 893$)$, truncaduras $(617$ y 606), raederas simples cóncavas (522) y puntas musterienses $(4,5,654,660,666$ y 675$)$. 


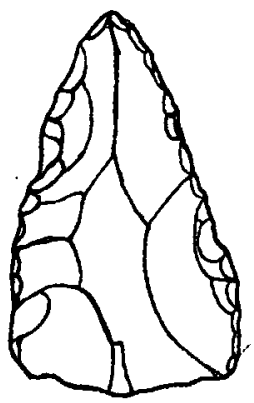

26

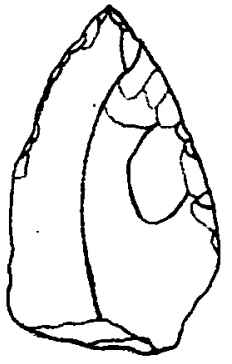

25
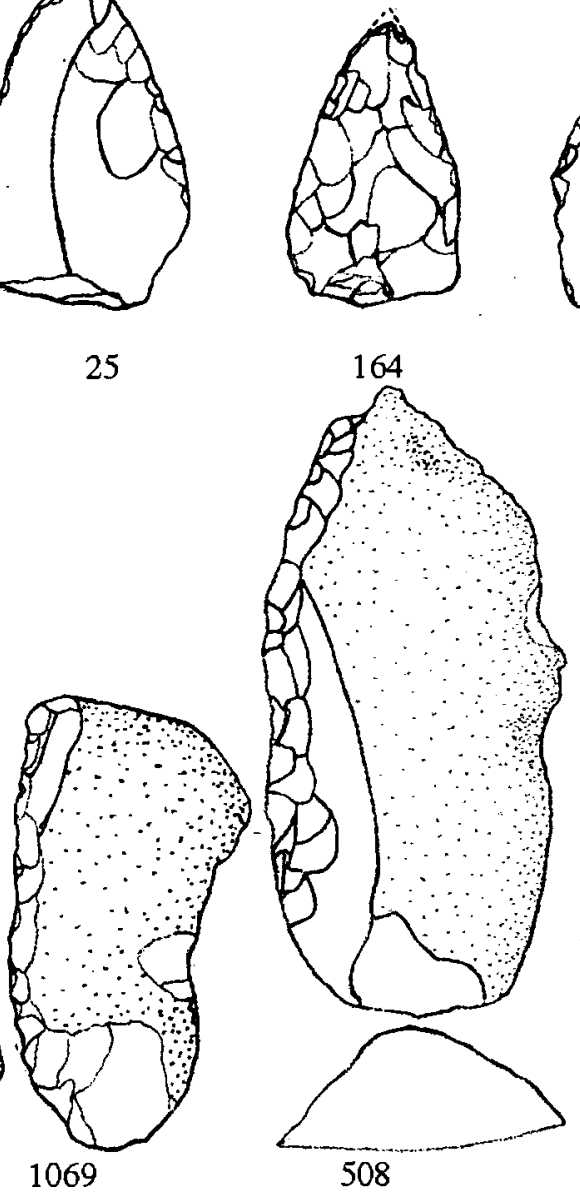

1069
2

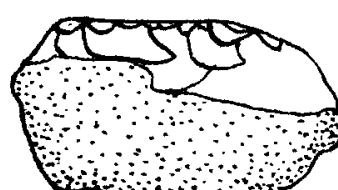

2
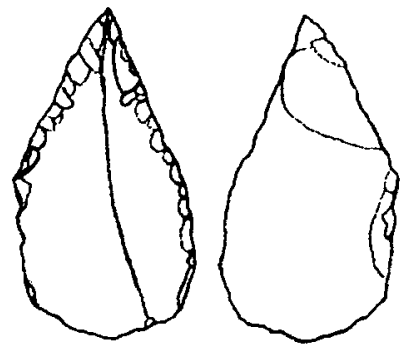

27
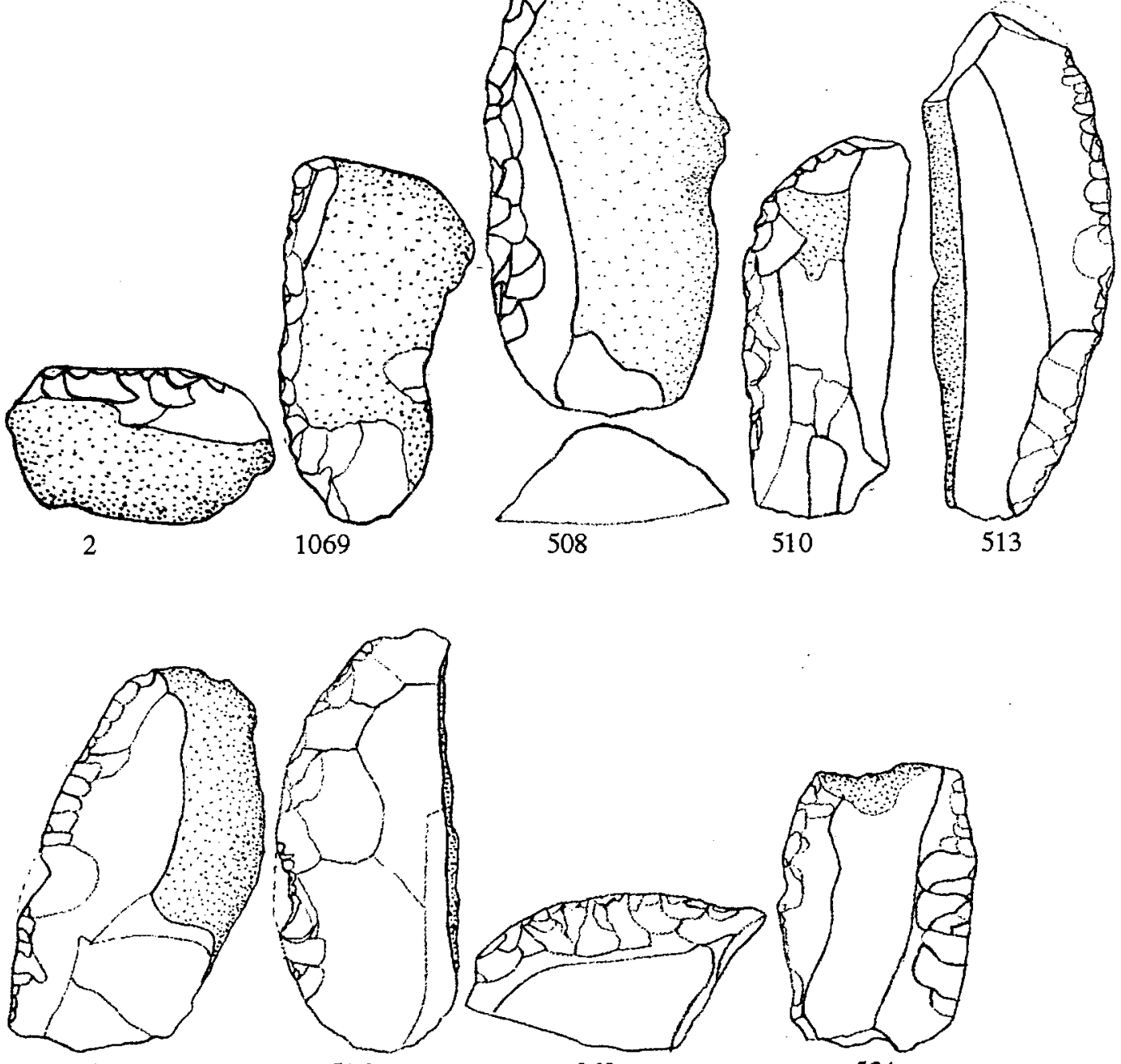

512
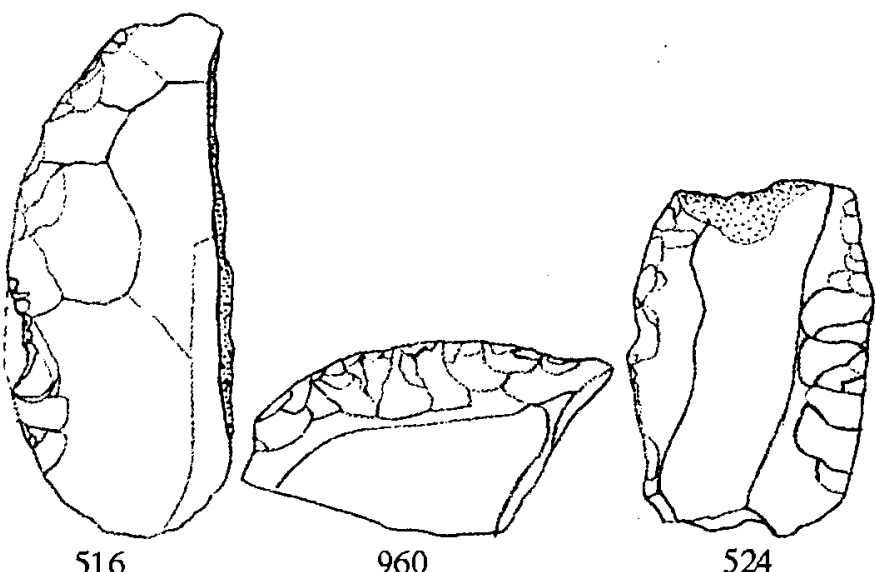

524

Lámina 2.- Puntas musterienses (25, 26, 27 y 164), raedera transversal recta (2), raederas simples convexas $(508,510,512,513,516$ y 1069), raedera transversal convexa $(960)$ y raedera doble convexa (524). 

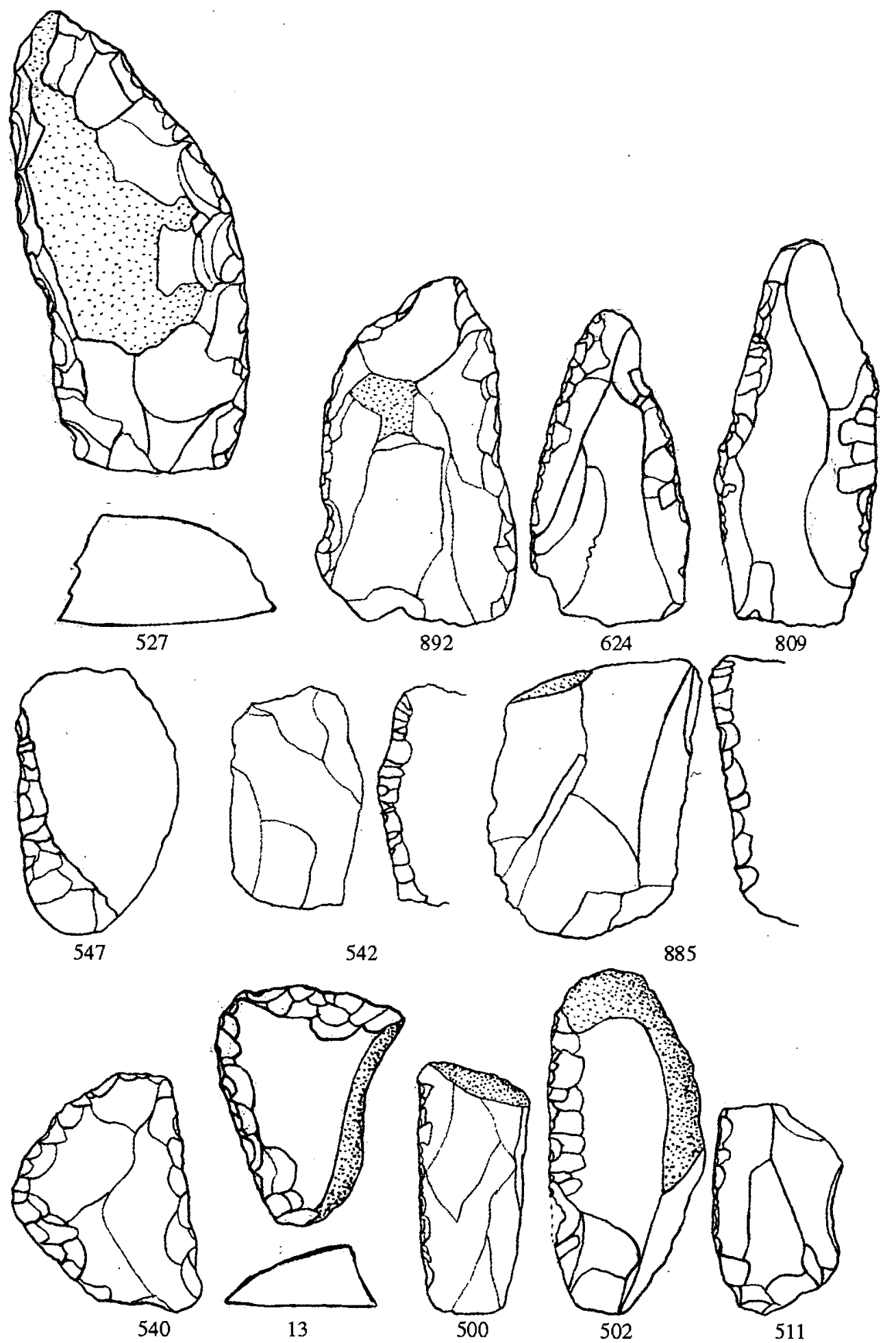

Lámina 3.- Raederas dobles convexas $(527,624,809$ y 892), raederas sobre cara plana $(542,547$ y 885$)$, raederas ladeadas (13 y 540), y raederas simples rectas $(500,502$ y 511$)$. 